\title{
BIBLIOGRAFÍA DE ARTE MUDÉJAR. ADDENDA (1995-1996)
}

\author{
Ana Reyes Pacios Lozano*
}

Siguiendo con la metodología empleada en la anterior addenda a la Bibliografía de arquitectura y techumbres mudéjares (1857-1991) , ofrecemos las últimas aportaciones al estudio del arte mudéjar, así como también algunas obras no localizadas hasta el momento. Recordamos que las referencias bibliográficas siguen la norma ISO 690-87.

\section{TEORÍA SOBRE EL ESTILO, INTERPRETACIÓN Y TERMINOLOGÍA}

Merlos Romero, María Magdalena. El término mudéjar en arte. Pasado y Presente. Solano: Revista de Humanidades del Instituto de Estudios Alonso Covarrubias, 1989, vol. $2, \mathrm{n}^{\circ} 2$, p. 29-35.

\section{FOCOS MUDÉJARES REGIONALES}

\section{ANDALUCÍA}

\section{CÓRDOBA}

Ramírez, Arturo. Restauración de alfarjes y taujeles del monasterio de Santa Clara de la Columna de Belalcazar (Córdoba). Restauración y Rehabilitación, 1995, vol. 2, $n^{\circ} 2$, p. 49-63.

\section{GRANADA}

López de Coca CASTAÑer, J.E. El trabajo de mudéjares y moriscos en el reino de Granada. En Actas VI Simposio Internacional de Mudejarismo, Teruel, 16-18 de septiembre de 1993. Teruel: Centro de Estudios Mudéjares del Instituto de Estudios Turolenses, 1995, p. 97-136.

\footnotetext{
* Departamento de Biblioteconomía y Documentación. Universidad Carlos III de Madrid.
}

1. Sharq al-Andalus, 12, 1995, pp. 613-630. 
QuioT, Alain. Jardines árabes en Granada y Marruecos. Similitud y variaciones. Cuadernos de la Alhambra, 1992, vol. 28, p. 61-80.

\section{HUELVA}

Pavón Maldonado, Basilio. Arquitectura islámica y mudéjar en Huelva y su provincia. Prototipos y espacios en la Andalucía Occidental. Huelva: Diputación Provincial, 1996. 252 p. ISBN 84-8163-069-1.

MÁLAGA

PÉrez BoYero, Enrique. La construcción de las iglesias en el marquesado de los Vélez. En Actas VI Simposio Internacional de Mudejarismo, Teruel, 16-18 de septiembre, 1993. Teruel: Centro de Estudios Mudéjares del Instituto de Estudios Turolenses, 1.995 , p. 811-831.

\section{SEVILLA}

Fernández Martín, María Mercedes. El artesonado del refectorio de la Cartuja de Santa María de las Cuevas de Sevilla. Laboratorio de Arte, 1994, nº 7, p. 303-311.

GONZÁLEZ JimÉnEZ, Manuel. El trabajo mudéjar en Andalucía. El caso de Sevilla (siglo XV). En Actas VI Simposio Internacional de Mudejarismo, Teruel, 16-18 de septiembre de 1993. Teruel: Centro de Estudios Mudéjares del Instituto de Estudios Turolenses, 1995, p. 39-56.

GonZÁLEZ RAmírez, María Isabel. El trazado geométrico en la ornamentación del Alcázar de Sevilla. Sevilla: Junta de Andalucía; Universidad de Sevilla, 1995. 314 p. ISBN 84-472-0239-9.

MEdiAnero Hernández, José $\mathrm{M}^{a}$. Las pinturas gótico-mudéjares de la capilla de la Quinta Angustia (Sevilla). Laboratorio de Arte, 1995, n 8, p. 25-50.

\section{ARAGÓN}

Alquézar Yánez, Eva Má; Arias SÁnchez, Isabel y Franco Mata, Ángela. Carpintería y elementos arquitectónicos mudéjares en el Museo Arqueológico Nacional procedentes de Aragón. En Actas VI Simposio Internacional de Mudejarismo, Teruel, 16-18 de septiembre, 1993. Teruel: Centro de Estudios Mudéjares del Instituto de Estudios Turolenses, 1995, p. 867-881.

Álvaro Zamora, María Isabel. El trabajo en los alfares mudéjares aragoneses. Aportación documental acerca de su obra, controles de su producción y formas de comercialización y venta. Revista Zurita, 1992 (1994), 65-66, p. 97-137.

- El trabajo de los mudéjares y los moriscos en Aragón y Navarra: estado de la cuestión. En Actas VI Simposio Internacional de Mudejarismo, Teruel, 16-18 de septiembre, 1993. Teruel: Centro de Estudios Mudéjares del Instituto de Estudios Turolenses, 1995, p. 7-38. 
Cabañero Subiza, Bernabé. Consideraciones sobre los talleres de decoración arquitectónica de la Marca Superior de los siglos X y XI y su identificación a partir de obras mudéjares. Sharq al-Andalus, 1995, n 12, p. 509-518.

FERNÁNDEZ JIMÉNEZ, Myriam I. Labores de algunas comunidades aragonesas, mudéjares y moriscos de Ricla, Villafeliche, Muel, La Almunia y Alfamén. En Actas VI Simposio Internacional de Mudejarismo, Teruel, 16-18 de septiembre de 1993. Teruel: Centro de Estudios Mudéjares del Instituto de Estudios Turolenses, 1995, p. 187-196.

Garcia Marco, Francisco Javier. El trabajo de los mudéjares de Daroca (Zaragoza) en la segunda mitad del siglo XV: evidencias en favor de la hipótesis de la complementariedad de las economías cristiana y mudéjar en el Aragón medieval. En Actas VI Simposio Internacional de Mudejarismo, Teruel, 16-18 de septiembre de 1993. Teruel: Centro de Estudios Mudéjares del Instituto de Estudios Turolenses, 1995, p. 167-186.

Navarro Echevarría, Pilar. Presencia toledana en las yeserías mudéjares aragonesas del siglo XVI. Sharq al-Andalus, 1995, n²12, p. 519-533.

\section{HuEsCA}

CABAÑERo SubIZA, Bernabé. Estudio de los tableros parietales de la mezquita aljama de Huesca, a partir de sus réplicas en el púlpito de la Sala de la Limosna. Notas sobre las influencias 'abbasíes en el arte de al-Andalus. Artigrama, 1994-95, n 11, p. 319-338.

- El púlpito de la Sala de la Limosna de la catedral de Huesca, una obra maestra próxima a su desaparición. Artigrama, 1994-95, n 11, p. 501-506.

COnTE Cazcarro, Anchel. La composición laboral de la aljama de moros de Huesca en los siglos XV-XVI. En Actas VI Simposio Internacional de Mudejarismo, Teruel, 16-18 de septiembre de 1993. Teruel: Centro de Estudios Mudéjares del Instituto de Estudios Turolenses, 1995, p. 137-142.

\section{TERUEL}

Rubio TORRero, Beatriz. Notas sobre las techumbres mudéjares turolenses. Sharq alAndalus, 1995, n 12, p. 535-546.

\section{ZARAGOZA}

Sanmiguel Mateo, Agustín. Un ejemplo de ductilidad del trabajo mudéjar: el abovedamiento de las torres-alminares en la comarca de Calatayud. En Actas VI Simposio Internacional de Mudejarismo. Teruel, 16-18 de septiembre, 1993. Teruel: Centro de Estudios Mudéjares del Instituto de Estudios Turolenses, 1995, p. 209-229.

RODRIGo EsTEBAN, M.L. Los mudéjares y su fuerza de trabajo en el ámbito urbano darocense (1423-1526). En Actas VI Simposio Internacional de Mudejarismo, Teruel, 16-18 de septiembre de 1993. Teruel: Centro de Estudios Mudéjares del Instituto de Estudios Turolenses, 1995, p. 143-165. 


\section{EXTREMADURA}

Mogollón Cano-Cortés, Pilar. El mudéjar en Extremadura. En Bataliús: El Reino Taifa de Badajoz. Estudios. Fernando Díaz (ed.) Madrid: Letrúmero, 1996, p. 189-200.

\section{GALICIA Y ZONA NORTE}

\section{OVIEDO}

Teijeira Pablos, María Dolores. El uso de la marquetería en las sillas corales tardogóticas: el caso ovetense. Boletín del Museo e Instituto "Camón Aznar", 1995, n ${ }^{\circ} 59$ 60, p. $237-246$.

\section{LA RIOJA}

SÁnchez Trujillano, Ma Teresa. El alfarje de Santo Domingo de la Calzada. En Actas VI Simposio Internacional de Mudejarismo. Teruel, 16-18 de septiembre, 1993. Teruel: Centro de Estudios Mudéjares del Instituto de Estudios Turolenses, 1995, p. 845-851.

\section{LeÓN Y CASTILla la Vieja}

Lavado Paradinas, Pedro J. Morerías castellano-leonesas. En Actas VI Simposio Internacional de Mudejarismo. Teruel, 16-18 de septiembre, 1993. Teruel: Centro de Estudios Mudéjares del Instituto de Estudios Turolenses, 1995, p. 719-751.

- Mudéjares y moriscos en los conventos de clarisas de Castilla y Léon. En Actas VI Simposio Internacional de Mudejarismo, Teruel, 16-18 de septiembre, 1993. Teruel: Centro de Estudios Mudéjares del Instituto de Estudios Turolenses, 1995, p. 391-419.

Pérez Higuera, María Teresa. El primer mudéjar castellano: casas y palacios. En Casas y palacios de Al-Andalus. Siglos XII-XIII. Barcelona: Lunwerg, 1995, p. 303-314.

Valdés Fernández, M., Pérez Higuera, M.T. y Lavado Paradinas, P.J. Arte mudéjar. Valladolid: Ámbito, 1996. 303 p. Historia del Arte de Castilla y León, tomo IV. ISBN 84-8183-004-6.

\section{BuRgos}

Concejo Díez, Ma Luisa. Una puerta mudéjar en el museo de Burgos. En Actas VI Simposio Internacional de Mudejarismo, Teruel, 16-18 de septiembre, 1993. Tertuel: Centro de Estudios Mudéjares del Instituto de Estudios Turolenses, 1995, p. 853-866.

\section{LEÓN}

ROLLÁN OrTIZ, Jaime Federico. Notas sobre la iglesia de Valdesaz de los Oteros. Tierras de León, 1991-1992, vol. 31, n 85-86, p. 151-172. 


\section{SALAMANCA}

García de Figuerola, Belén. Techumbres mudéjares en Salamanca. Salamanca: Ediciones Diputación de Salamanca, 1996. 203 p. ISBN 84-7797-098-X.

\section{SEGOVIA}

Hernández San Frutos, María del Carmen. La iglesia del convento de Santa Isabel en Segovia. Estudios Segovianos, 1995, vol. 36, n93, p. 83-120.

SORIA

Pavón Maldonado, Basilio. En torno a la supuesta sinagoga de Medinacelli (Soria). Nuevos datos artísticos. Sefarad, 1978, vol. 38, n², p. 309-317.

NAVARRA

Véase:

Álvaro Zamora, María Isabel. El trabajo de los mudéjares...

CABAÑERo SubizA, Bernabé. Consideraciones sobre los talleres...

\section{TOLEDO Y ZONA CENTRO}

\section{Guadalajara}

Pradillo y Esteban, Pedro José. La desaparecida parroquia de San Gil de Guadalajara: Estado de la cuestión y nuevas aportaciones. Wad-Al-Hayara, 1994, 21, p. 211-256.

MADRID

ToAjas Roger, María Angeles. Carpintería y arquitectura del Renacimiento en Madrid: las techumbres de la parroquial de Camarma de Esteruelas. Anales de Historia del Arte, 1995, n 5, p. 19-54.

- En torno al llamado "estilo Cisneros": la techumbre del paraninfo de Alcalá de Henares. En La Universidad Complutense y las Artes [Congreso Nacional, Madrid, 1993]. Madrid: Servicio de Publicaciones Universidad Complutense, 1995, p. 75-95.

\section{TOLEDO}

BASTOS, Victoria y LAFORA, Carlos. El foco mudéjar toledano: Itinerarios Mudéjares en Castilla-La Mancha. Toledo: Junta de Comunidades de Castilla-La Mancha, 1996. 144 p. ISBN 84-7788-161-8.

CAmpos Romero, $\mathrm{M}^{\mathrm{a}}$ Ángeles. Imaginemos un palacio mudéjar del siglo XIV en la llamada Casa de Mesa de Toledo. En Actas VI Simposio Internacional de $\mathrm{Mu}$ dejarismo, Teruel, 16-18 de septiembre, 1993. Teruel: Centro de Estudios Mudéjares del Instituto de Estudios Turolenses, 1995, p. 883-894. 